\title{
Fundamentals of Building Heat Transfer
}

\author{
Tamami Kusuda \\ Institute for Applied Technology, National Bureau of Standards, Washington, D.C. 20234
}

(July 5, 1977)

\begin{abstract}
Basic problems and unique features of building heat transfer are described in relation to the heating and cooling load calculation, which is a starting point for building energy consumption analysis and equipment sizing. Detailed discussion is given of the relationship between heat loss (heat gain) and heating load (cooling load). Also outlined is a discussion of the multi-space heat transfer problem in which the air and heat exchange equations among adjacent spaces in a building are solved simultaneously with the radiant heat exchange equations for the surfaces of each room.
\end{abstract}

Key words: Air-leakage; dynamic heat transfer; energy analysis; heat and cooling loads; heat loss and heat gain; multi-room problems.

\section{Nomenclature}

$\begin{array}{ll}A & \text { Matrix element as defined in the text } \\ B & \text { Mátrix element as defined in the text } \\ C_{P} & \text { Specific heat of air } \\ D B & \text { Outdoor dry-bulb temperature } \\ F & \text { Exterior surface convective heat transfer coef- } \\ & \text { ficient } \\ G & \text { Mass air flow between adjacent spaces } \\ H & \text { Interior surface convective heat transfer coeffi- } \\ & \text { cient } \\ H_{k} & \text { Interior surface radiative heat transfer coeffi- } \\ I & \text { cient } \\ Q G & \begin{array}{l}\text { Solar radiation indicent upon an exterior sur- } \\ \text { face }\end{array} \\ r & \begin{array}{l}\text { Strength of heat source/sink } \\ \text { Radiant heat incident upon each interior sur- } \\ \text { face }\end{array}\end{array}$
QS Net long-wave radiant heat to an exterior sur- face
$S \quad$ Interior surface area
$T A$ or $T_{A} \quad$ Space air temperature
TI Interior surface temperature
$T O$ or $\mathrm{T}_{O} \quad$ Exterior surface temperature
TS Supply air temperature to a space
$X_{n}, Y_{n}, Z_{n} \quad(n=1) \ldots N$ thermal response factors
$\alpha \quad$ solar absorptance of exterior surface
$\tau \quad$ solar transmittance of window
Subscripts
$t \quad$ time
Superscripts
$i, j \quad$ denotes $i$ th and $j$ th spaces
$k, l \quad$ denotes $k$ th and $l$ th surfaces

\section{Introduction}

The purpose of this paper is to summarize state-of-the-art information on various aspects of building heat transfer, and to discuss two selected subjects in detail; namely, the multispace heat transfer problem and the relationship between heat loss and heating load.

Building heat transfer calculations are performed for different applications such as:

(a) Heat loss and heat gain through exterior envelope-

- conduction through exterior envelope,

- conduction heat transfer through basement walls and slab-on-grade floor (... to semi-infinite region),

- short wavelength (or solar heat) transmission, absorption, and reflection for fenestration,

- air leakage through exterior envelopes as well as the interior partition walls, ceilings and floors,
- thermal storage in exterior masses of buildings.

(b) Interior environmental analyses-

- radiant heat exchange among interior surfaces and heat sink/sources,

- convective heat exchange between room air and room interior surfaces,

- room air convection . . . inter- and intra-room convective motion,

- convective and radiative heat transfer of internal heat sources such as heaters, coolers and occupants,

- thermal storage in interior masses.

(c) Material or building element-related problems -

- cold-bridge effect,

- convection within porous insulation,

- moisture condensation due to simultaneous flow of air, moisture, and heat. 
Basic to all of these applications is the fact that heat transfer processes for buildings are usually ill defined, time dependent, multi-dimensional, and in many cases non-linear. Thus all the solutions available today for any one of these applications are based upon numerous simplifying assumptions. In many cases refined and advanced solutions may be available, but they tend to be overly complex and have very little practical value. In addition, until recently, at least in the United States, most applications of advanced heat-transfer analysis have traditionally been explored by the aerospace and nuclear power industries. For this reason, many of the challenging problems in building heat transfer have been left unsolved.

\section{Conduction Heat Transfer}

Conduction heat transfer problems relevant to buildings include:

(a) Exterior wall conduction-

- transient heat transfer responding to climatic effects, such as temperature fluctuation, solar radiation, wind and precipitation; thermal storage . . . damping and lag effect; and cold-bridge effect (two-dimensional and non-linear heat flow path).

(b) Interior mass conduction -

- heat storage in partition walls, floor/ceiling sandwich.

(c) Conversion from heat gain/loss to cooling and heating load.

(d) Ground heat loss from slab-on-grade floor and basement walls.

Most of the building heat conduction problems are multidimensional and transient, requiring numerical (either finite difference and/or finite element analyses) or analog computer-simulation calculation. For one-dimensional multilayer problems, numerous analytical solutions are available, for both steady-state and transient conditions. These solutions are frequently used for heat gain and loss calculation for exterior envelopes and heat storage in interior structures. Most notable contributions in recent years for the multilayer problems are the thermal-time-constant concept of Raychaudhuri [1], ${ }^{1}$ the admittance solution of Laudon [2], the frequency response solution of Muncey [3] and the response factor solution of Mitalas and Arseneault [4]. These solutions permit the accurate evaluation of heat conduction through building walls, roofs and floors so long as the heat flow is normal to the surface. Missing from these methods and awaiting development are similar solutions for multidimensional problems related to building corners, floor slabon-grade, and basement walls.

\section{Convection Heat Transfer}

Convective heat transfer problems relevant to buildings include:

\footnotetext{
${ }^{1}$ Figures in brackets indicate the literature references on page
}

(a) Heat transfer at the exterior surface considering both wind and surface roughness characteristics,

(b) Convection in and through the cavity walls,

(c) Convection between the window glass panes,

(d) Inter- and intra-space air motion due to temperature and pressure gradient,

(e) Convection heat transfer due to air leakage through exterior walls.

(f) Convection heat transfer within the porous insulating structure.

The surface heat transfer coefficients are affected by the nature of the air boundary layer which is strongly influenced by the surface geometry, temperature gradient, and the flow outside the boundary layer region. Unfortunately most of the textbook solutions and analytical expression available are based on very simplistic boundary conditions. They should be considered as only approximate solutions to the real building problems. The air flow around the building, along the internal surfaces, and in the wall cavities is very complex, erratic and not conducive to exact analytical solutions. Moreover, the actual building surface geometry is seldom well defined.

Many inexperienced building heat transfer analysts have mistaken notions that the exterior surface or interior surface heat transfer coefficients as found in the heat transfer textbook or in the ASHRAE Handbook of Fundamentals [5] are absolutely accurate. This notion was conveyed to the author recently in one of the thermographic heat-flux measurement meetings, at which an attempt was made to convert the surface temperature measured by a sophisticated infrared scanning apparatus to a heat flux value by applying the ASHRAE Handbook value [5] for the surface heat transfer coefficient. In reality, the surface heat transfer coefficient could differ from the published value by as much as $100 \%$, depending upon the local wind gust and the irregularity of the surface geometry. The fact is that, except those reported by Ito and Kimura [6], the exterior surface heat transfer coefficients for actual buildings have never been studied experimentally. The same is true for the interior surface heat transfer coefficients, except for the original work of Wilkes and Peterson [7].

A number of studies have been reported in recent years in which numerical solutions of the Navier Stokes fluid dynamics equation and the energy equation were obtained for twodimensional air flow within a confined space for the laminarflow regime characteristics of room convection, and into the turbulent-flow regime (the Grashoff number of $10^{12}$ or larger). In addition, steady turbulent-flow solutions to the modified Navier-Stokes equations were obtained by Nielsen [9]. The computer time and computer memory size required to deal with realistic three-dimensional flow problems in a room are formidable. Bankvall [10] and Tien [11] are studying flow equations within porous media, and Tien is extending the solution to partially filled insulation cavities, as well as to the permeable boundary surface problems, to simulate air leakage in insulated walls. 


\section{Radiant Heat Exchange}

Radiation heat transfer is very important in building application in the following areas:

(a) Short-wavelength radiation:

- solar heat absorption on opaque exterior surfaces,

- solar heat transmission through transparent surfaces,

- solar heat absorption and reflection by interior building surfaces,

- absorption and reflection of solar heat by window glass.

(b) Long-wavelength radiation:

- heat emission by the exterior surfaces to the sky,

- heat exchange among interior surfaces,

- heat exchange between interior surfaces and occupants,

- heat exchange between the lighting fixture and interior surfaces.

While extensive work has been reported in the area of solar energy exchange with exterior surfaces, basic irradiation data are still insufficient with respect to the diffuse sky radiation component, particularly for vertical surfaces and for cloudy sky conditions.

Perhaps the most difficult and tedious problem in dealing with solar heat exchange analysis for building applications is the analysis of direct or beam radiation that is transmitted through fenestration, absorbed, reflected and reemitted by the interior surfaces. Because of the complex geometry of the time dependent shade and sunlight patterns, exact solutions to simulate realistic solar heat exchange in a room are virtually impossible. It is usually assumed that the interior surface is gray (non-spectral) and diffuse (no specular reflection), and the solar heat is diffused once it enters through the window and interior shading devices.

The long-wavelength radiant heat emission to the sky from the building exterior surface has not been well explored except for the clear sky condition, although some work is going on at CSTB in France [12].

\section{Heating and Cooling Loads Calculations}

Because of the increased urgency for energy conservation in the design of buildings, and because the essential part of the energy conservation design is the accurate determination of building heating and cooling requirements, a great emphasis has been placed upon load calculations in recent years.

It might be mentioned that at least in the United States past practices for heating and cooling load calculations were based upon steady-state heat transfer performed at design conditions that represent extremely cold and hot days. This is because the heating and cooling loads in the United States were calculated solely for the purpose of selecting and sizing the heating and cooling equipment to provide comfort for the extremes of climatic conditions. Since these extreme design conditions rarely represent day-by-day aver- age operating conditions, the heating and cooling equipment designed or selected is usually oversized and operates at part-load conditions that result in poor efficiency.

On the other hand, the European and Japanese engineers have been predicting indoor temperature as a function of the ever-changing outdoor climate conditions. Their interest has been primarily to determine the need for air-conditioning by estimating the number of hours in the summer when the indoor temperature could exceed the comfort requirement.

Since most North American homes and commercial buildings are already air-conditioned and centrally heated, major emphasis in the United States is to be able to predict energy consumption by this heating and cooling equipment. It has been well accepted in the United States that the most accurate way of estimating the annual energy consumption of a given building is to simulate the heat transfer performance of the building and the performance of its heating, ventilating and air conditioning systems on an hourly basis throughout the year, thus requiring 8760 calculations. During the past decade, a number of sophisticated computer programs have been developed to do the hourly simulation [13]. The American Society for Heating, Refrigerating and Air-Conditioning Engineers has, for example, developed recommended procedures $[14,15]$ to simulate the building heat transfer, and system and equipment performances.

A difficult portion of this hourly simulation approach is the coupling between the building heating and cooling requirement and the available capabilities of the building heating and cooling systems-especially for the building with many zones, each requiring different heating and cooling with respect to time-dependent use schedule and occupancy patterns. The coupling calculation becomes especially difficult when the heating and cooling capacity provided by the heat distribution system and by the building central plant cannot match with the space heating and cooling requirements.

Thus when a mismatch between the calculated requirement and the available system capacity occurs, the space temperature drifts from the set-point for which the original load calculation was performed. The amount of this drift is dependent upon the thermal storage characteristics of the space under consideration, the operating characteristics of the heat distribution system, and the part-load or the overload characteristics of the central heating and cooling plant. To the best of this author's knowledge, no existing energy analysis computer program can handle this problem in an exact manner.

Simultaneous calculations of multi-space heating and cooling requirements, together with the heating and cooling capability of central HVAC systems, under dynamic conditions, (where the climate as well as operating parameters are constantly changing) are extremely difficult. Thus a common American practice is to calculate the space heating and cooling requirement at a given set of required space temperature conditions. The coupling between the load and the system capacity is evaluated by the use of the weighting factor concept. The weighting factors are transfer functions generated by Mitalas [4] for three typical rooms representing light, medium and heavy construction, by solving detailed room surface heat balance equations.

\subsection{Heat Balance Equation at Exterior Surfaces}

The building exterior surfaces receive solar radiation, exchange long-wavelength radiation with the surroundings 
including the sky, exchange heat with the outside air by the convection process, and conduct heat into the solid structure. Equation (1) represents a complete heat balance on the exterior surface with the response factors being used for the heat conduction term [4].

$$
\begin{aligned}
q_{t}^{(i, k)}= & \sum_{n=0}^{\infty} Y_{n}^{(i, k)} \cdot T I_{t-n}^{(i, k)} \\
& -\sum_{n=o}^{\infty} Z_{n}^{(i, k)} \cdot T 0_{t-n}^{(i, k)} \\
= & F^{(i, k)} \cdot\left(T 0_{t}^{(i, k)}-D B_{t}\right)+Q S_{t}^{(i, k)}-\alpha \cdot I_{t} .
\end{aligned}
$$

\subsection{Heat Balance Equation at Interior Surfaces (Inter-Space Heat Exchange)}

Equation (2) shows all the components involved in the heat balance of an interior surface; namely, the long-wavelength radiant heat exchange with the rest of the surfaces, convective heat exchange with the air, incident solar radiation (through the windows), long-wavelength radiation from lighting and equipment, and heat stored into the solid material, which is expressed in response-factor terms.

$$
\begin{aligned}
q_{t}^{(i, k)}= & \sum_{n=0}^{\infty} X_{n}^{(i, k)} T I_{t-n}^{(i, k)} \\
& -\sum_{n=0}^{\infty} Y_{n}^{(i, k)} T 0_{t-n}^{(i, k)} \\
= & H^{(i, k)}\left(T A_{t}^{(i)}-T I_{t}^{(i, k)}\right) \\
& +\sum_{j=1}^{N_{i}} H_{j}^{(i, k)}\left(T I_{t}^{(i, j)}-T I_{k}^{(i, k)}\right)+r_{t}^{(i, k)}
\end{aligned}
$$

By rearranging the terms, eq (2) becomes

$$
\begin{aligned}
\sum_{j=1}^{N_{i}} A_{j}^{(i, k)} T I_{t}^{(i, j)}+ & A I^{(i, k)} T A_{t}^{(i)} \\
& +A O^{(i, k)} T O_{t}^{(i, k)}=B^{(i, k)} \quad k=1, N_{i}
\end{aligned}
$$

where $\mathrm{N}_{i}=$ total number of heat transfer surfaces in the $i$ th room

$$
\begin{aligned}
B^{(i, k)}= & -\sum_{n=1}^{\infty} X_{n}^{(i, k)} T I_{t-n}^{(i, k)} \\
& +\sum_{n=1}^{\infty} Y_{n}^{(i, k)} T O_{t-n}^{(i, k)}+r_{t}^{(i, k)} \\
A_{j}^{(i, k)}= & X_{0}^{(i, k)}+H^{(i, k)}+\sum_{j=1}^{N_{i}} H_{j}^{(i, k)} \\
A_{K}^{(i, k)}= & -H_{K}^{(i, k)} \\
A O^{(i, k)}= & Y_{0}^{(i, k)}
\end{aligned}
$$

and

$$
A I^{(i, k)}=H^{(i, k)}
$$

Equations similar to (3) should be prepared for all the interior surfaces in a given space (room). On the other hand, the overall heat balance equation of the space air should include the convection heat exchange with the surfaces, heat sources, air leaked into the space, and heat given off and supplied by the heat sources/sinks (including space conditioning devices), as follows:

$$
\begin{aligned}
\sum_{k=1}^{N_{i}} H^{(i, k)}\left(T I_{t}^{(i, k)}\right. & \left.-T A_{t}^{(i)}\right) S^{(i, k)} \\
+ & \sum_{k=1}^{N_{i}} G C_{p}^{(i, k)}\left(A T_{t}^{(i, k)}-T A_{t}^{(i)}\right)+Q G^{(i)}=0
\end{aligned}
$$

By letting

$$
\begin{aligned}
M_{i} & =N_{i}+1 \\
A_{K}^{\left(i \cdot M_{i}\right)} & =H^{(i, k)} S^{(i, k)} \\
A I^{\left(i, M_{i}\right)} & =-\sum_{k=1}^{N_{i}} H^{(i, k)} S^{(i, k)}-\sum_{k=1}^{N_{i}} G^{i, k} \cdot C_{p} \\
A O_{k}^{\left(i, M_{i}\right)} & =G^{(i, k)} C_{p} \\
B^{\left(i, M_{i}\right)} & =-Q G^{(i)} .
\end{aligned}
$$

The space heat balance equation (4) then becomes:

$$
\begin{aligned}
\sum_{k=1}^{N_{i}} A_{K}^{\left(i, M_{i}\right)} T I_{t}^{i, k}+A I^{\left(i, M_{i}\right)} & =T A_{t}^{(i)} \\
& +\sum_{k=1}^{N_{i}} A O_{K}^{\left(i, M_{i}\right)} \cdot A T_{t}^{(i, K)}=B^{\left(i, M_{i}\right)}
\end{aligned}
$$

A set of $\left(N_{i}+1\right)$ simultaneous equations comprising $\mathrm{N}_{i}$ equations of type (3) and equations (5) must be solved simultaneously for a given space to yield the interior surface temperature and space air temperature.

\subsection{Inter-Space (Inter-Room) Heat Exchange}

When the space under consideration in the previous section is adjacent to other spaces, all of the inner surface temperatures and air temperatures for all of the adjacent spaces are being affected by one another. Figure 1 illustrates the heat transfer process through a boundary wall between the $i$ th space and $j$ th space, indicating conductive and convective heat exchange between the two spaces. A simplified and yet relatively typical four-space problem, as depicted in figure 2 , is used herein to illustrate the complexity of the multi-room problem. 


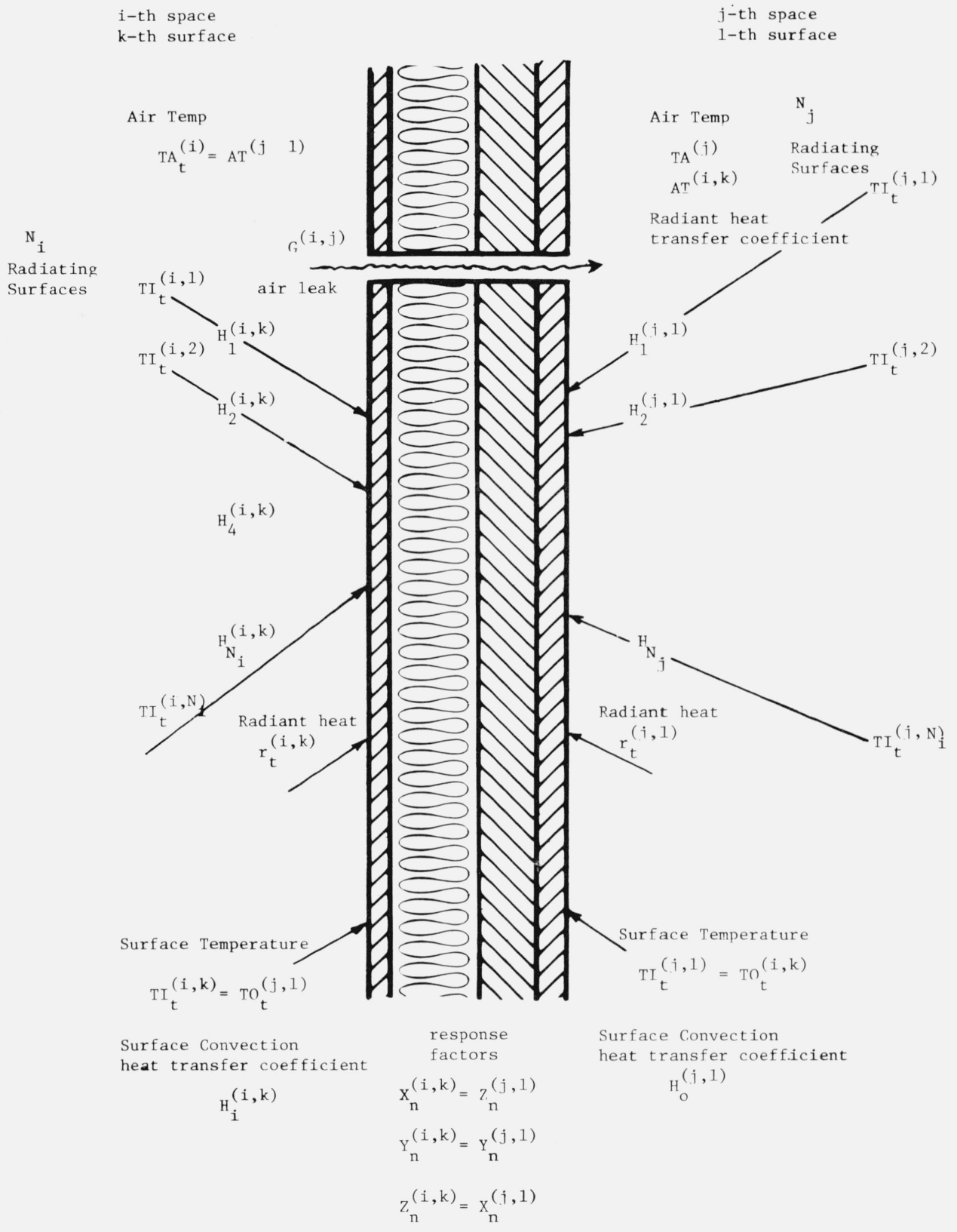

FIGURE 1. Heat transfer of a partition wall between th ith and jth space.

In order to simplify the mathematical manipulation, figure 3 is provided to show the interaction of four spaces by thermal coupling through adjacent interior surfaces. Figure 4 shows the matrix form of the complete heat balance equation to be solved for this four-space problem using matrix notations provided in equations (2) and (3). In this matrix presentation air leakage between the adjacent spaces is presented as a constant $G^{(i k)}$. Air leakage is, however, in reality a function of the temperature difference and pressure difference between the space due to wind effect. Tamura and Sanders [16] developed and later Fothergill [17] ex- panded a comprehensive computer program to calculate air flow between building spaces as affected by the external wind pressure as well as by the thermal stack effect. The program was primarily developed for the study of smoke migration pattern analysis under a fire research program. It does not incorporate the thermal storage characteristics of the building internal thermal mass; however, there is a real need for an efficient computation procedure by which the multi-space air and heat transfer process can be analyzed in a comprehensive manner.

The above discussions indicate that a comprehensive 


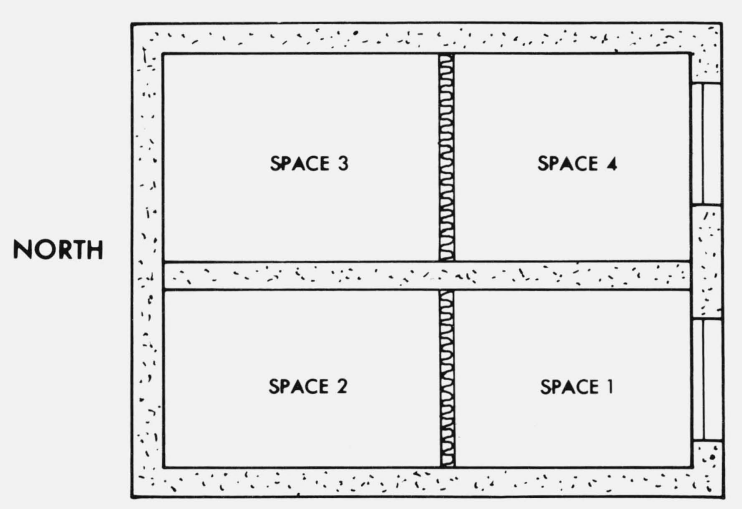

SOUTH

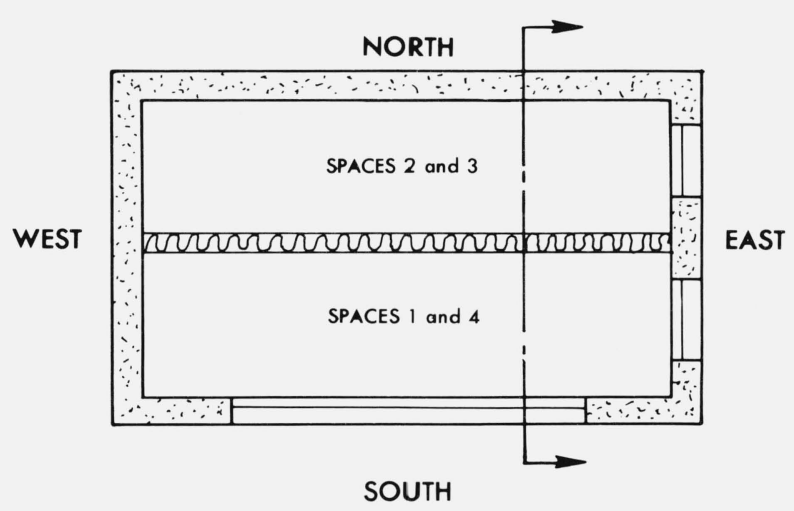

FIGURE 2. Plan of a sample 4-space model.
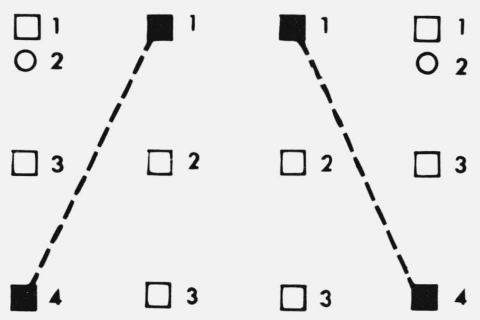

SOUTH

WEST

NORTH

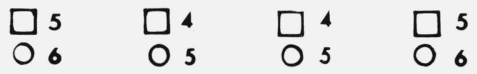

EAST

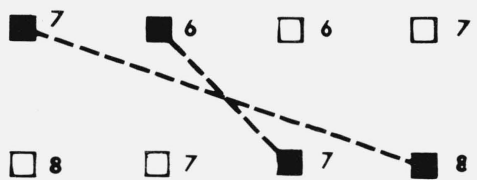

ROOF KEILING

FLOOR

D OPAQUE WALL ....EXTEROR

- opaque wall .....NTERior

O TRANSPARENT WALL (WINDOW)

\section{$\triangle$ OPEN PASSAGE}

FIGURE 3. Interior-exterior wall relationship of a 4-space model as depicted in figure 2.

Difficulty arises, however, in simulating the regulation or control of $G S$ and $T C$ in the computational process. The heat exchanges among the space thermostat, space air and room surfaces enter the heat balance equations, thereby increasing the complexity of the problem. In addition, due to the time response characteristic of the thermostat, the simulation of the control system requires minute-by-minute calculations, rather than the hour-by-hour calculations.

\section{Summary}

Heat source/sink term $Q G$ indicated in eq (4) could supply air system. If the supply air quantity and its temperature are expressed as $G S_{t}$ and $T C_{t}$ respectively, the term $Q G$ takes on the value $G S_{t} \cdot C_{P} \cdot\left(T C_{t}-T A_{t}\right)$.

In this manner the space air temperature can be determined as a balance between the space heating and cooling requirement and the heating and cooling capacity of the HVAC supply air system. The values of $G S$ and $T C$ may vary, however, according to the mode and type of the building air distribution system. For example, a constant air volume system would provide $G S$ constant and regulate $T C$, whereas a variable volume system would regulate $G S$ with TC held constant.
Basic problems and difficulties inherent in the comprehensive analysis of building heat transfer are due to many parameters which are ill defined and some of which are time dependent and multi-dimensional.

One of the crucial areas for building heat transfer analysis is the hour-by-hour simulation of the balancing process between the heating and cooling requirements of many spaces and the central heating and cooling capacity of the building. Analytical solutions available for any of these problems are based upon simplistic assumptions.

Detailed discussions of radiant heat exchange effects for building heat loss calculations are included in the appendix. 


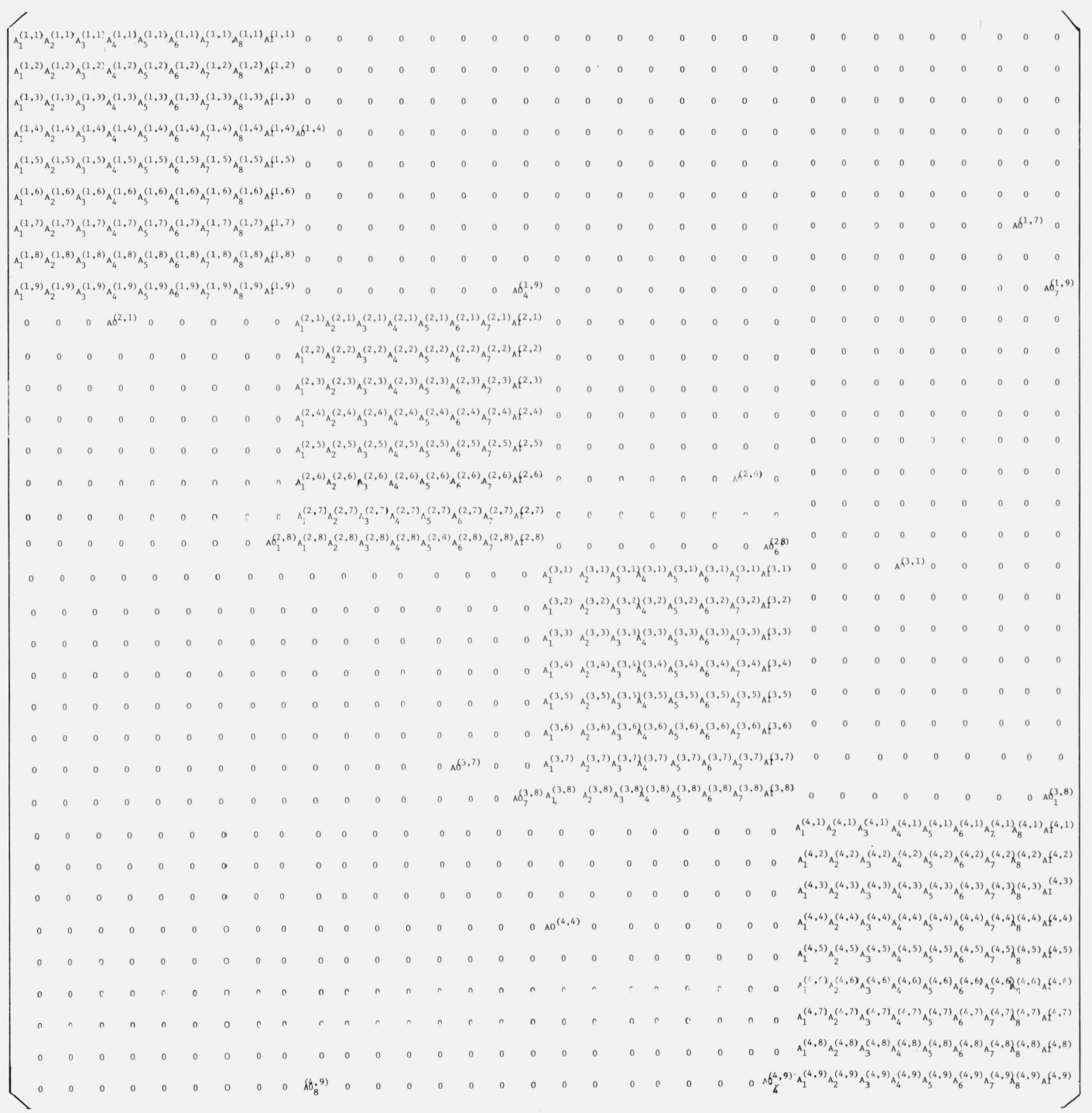

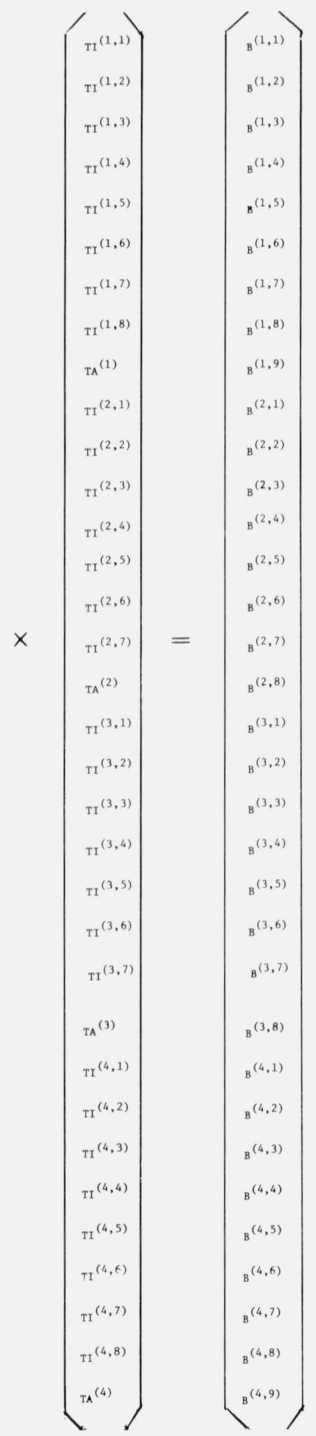

FIGURE 4. Heat balance equation of a 4-space model. 


\section{References}

[1] Raychaudhuri, B. C., Transient thermal response of enclosures; the integrated thermal time constant, International J. Heat Mass Transfer 8, 1439 (1965).

[2] Laudon, A. G., Summertime Temperatures in Buildings, Building Research Studies, 1968. Building Research Establishment, Building Research Station, Garston, Watford, WD2 7JR.

[3] Muncey, R. W., The thermal response of a building to sudden changes of temperatures or heat flow, Australian J. Sci. 14, 123, 1963.

[4] Mitalas, G. P., and Arsenault, J. G., Fortran IV program to calculate Z-transfer functions for the calculation of transient heat transfer through walls and roofs, use of computers for environmental engineering related to buildings, NBS-BSS 39, 1971, pp. 663-668.

[5] American Society for Heating, Refrigerating and Air Conditioning Engineers, 1977.

[6] Ito, N., and Kimura, K., Field Experiment Study on the Convective Heat Transfer Coefficient of Exterior Surfaces of a Building, ASHRAE Trans. 78, 1 (1970).

[7] Wilkes, G. B., and Petersen, C. M. F., Radiation and convection from surfaces in various positions, ASHVE Trans. 44, 1, (1938), pp. 513.

[8] Fromm, J. E., A numerical method for computing the non-linear, time dependent buoyant circulation of air in rooms, use of computers for environmental engineering related to buildings, NBS-BSS 39, (1971) pp. 451-467.

[9] Nielsen, P. V., Flow in Air Conditioned Rooms, Ph.D. Thesis, Technical University of Denmark, Nordberg, 1974.

[10] Bankvall, C. G., Natural Convective Heat Transfer in Insulated Structures, Lund Institute of Technology, (Sweden) Report 38 , 1972.

[11] Tien, C. L., and Burns, P. J., Convection in a Vertical Slot Filled with Porous Insulation, International Heat and Mass Transfer, Dubrovnik, Yugoslavia, 1977.

[12] Bertolo, L., Instrumentation for Measuring Heat Transfer to the Sky, an unpublished CSTB document, CSTB, France, circa 1975.

[13] Crall, C., Bibliography on Available Computer Programs in the General Area of Heating, Refrigerating, Air Conditioning and Ventilating, ASHRAE Research Project Report GPR-153, October 1975.

[14] Task Group on Energy Requirements, Procedure to Determine Heating and Cooling Loads for Computerized Energy Calculations for Buildings, special ASHRAE Bulletin, 1974

[15] Stoecker, W. C., Procedure to Simulate HVAC System and Equipment for Computerized Energy Calculations, Special ASHRAE Bulletin, 1974

[16] Tamura, G., and Sanders, D., A Fortran IV Program to Simulate Air Movement in Multi-Story Buildings, DBR-NRC Computer Program No. 35, March 1973.

[17] Fothergill, J. W., et al, Development of an Air Movement Simulation Program, NBS Contract Report, Integrated Systems Inc., Rockville, Maryland, 1976.

\section{Appendix. Heat Load Versus Heat Loss for Central Heating Systems}

When a building is centrally heated, the heating of a given space is provided by the hot supply air to the system. The hot air entering the space is usually assumed instantly mixed with the space air to raise the space temperature. Thus the manner in which the warm space air loses its heat to the cold exterior surfaces present in the space dictates the heating requirement. In many calculations, however, it is tacitly assumed that the space air temperature is equal to the space surface temperatures and the heating load is calculated by a simple formula such as:

$$
Q=U_{0} \cdot\left(T_{A}-T_{0}\right) \cdot S_{0}
$$

where $U_{0}=$ overall heat transfer coefficient of exterior surface

$T_{\boldsymbol{A}}=$ room air temperature

$T_{0}=$ outdoor temperature

$S_{0}=$ exterior surface areas.
This simple relationship is incompatible with reality, where the space surface temperature is seldom equal to the space air temperature.

To examine the difference in results between the common assumption and the exact solution, a simple room of one single-glazed window was studied. In this room the walls are assumed massless and have the same overall and surface heat transfer coefficients and the same interior surface temperatures, and are exposed to the same outdoor air temperature as shown in figure A-1. Ignoring the solar heat absorbed by the glass, the heat exchange equation for the inner surface of the window for the model will be:

$$
\begin{aligned}
H_{G} \cdot\left(T_{S G}-T_{A}\right)+H_{G W} \cdot\left(T_{S G}\right. & \left.-T_{S W}\right) \\
& +U_{G T} \cdot\left(T_{S G}-T_{0}\right)=0
\end{aligned}
$$

where $H_{G}=$ convective heat transfer coefficient over the interior surface of the window.

$H_{G W}=$ radiative heat transfer coefficient of the window to the interior surface of the opaque wall.

$U_{G T}=$ thermal conductance between the inner surface of window and outside ambient

$T_{S G}=$ interior surface temperature of the window

$T_{S W}=$ interior surface temperature of .ll the walls

$T_{A}=$ room air temperature

$T_{0}=$ outside ambient temperature.

To

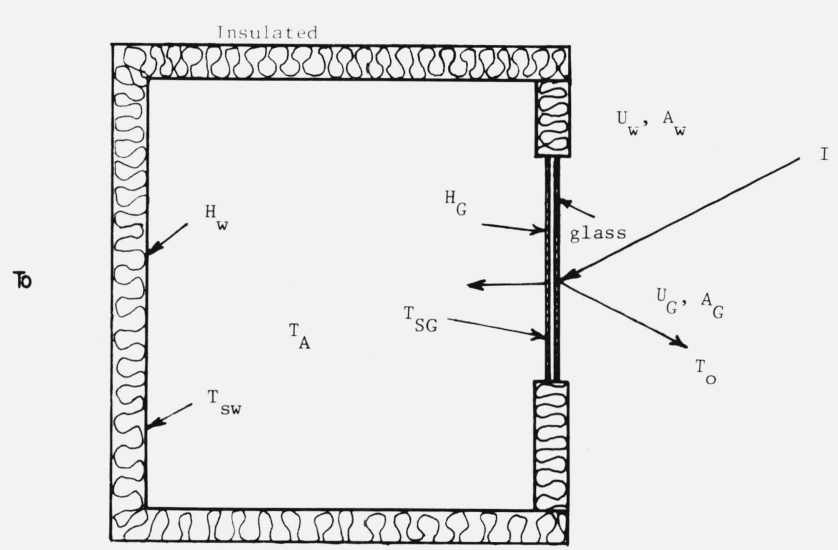

To

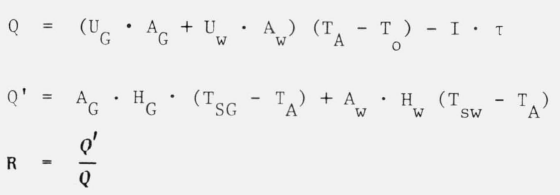

FIGURE A-1. A simplified room with all the opaque envelopes having the same thermal characteristics.

A similar equation can be constructed for the wall portion, again ignoring the heat storage effect, as follows: 


$$
H_{W} \cdot\left(T_{S W}-T_{A}\right)+H_{G W} \cdot\left(T_{S W}-T_{S G}\right)
$$

$$
+U_{W T} \cdot\left(T_{S W}-T_{0}\right)=I \cdot \frac{A_{G}}{A_{W}} \tau
$$

where $H_{W}=$ convective heat transfer coefficient over the interior surface of the wall

$H_{W G}=$ radiative heat transfer coefficient of the interior surface of the wall to the window

$U_{W T}=$ thermal conductance between the interior surfaces of the wall and the outside ambient

$I=$ solar radiation incident upon the window

$\tau=$ solar transmittance through the window

$A_{G}=$ window area

$A_{W}=$ wall area.

The values of $U_{\boldsymbol{G} T}$ and $U_{\boldsymbol{W T}}$ can be calculated by knowing the overall heat transfer coefficient for window $U_{G}$ and that for wall $U_{\boldsymbol{W}}$ as follows:

$$
\begin{gathered}
\frac{1}{U_{G T}}=\frac{1}{U_{G}}-\frac{1}{H_{G}+H_{G W}} \\
\frac{1}{U_{W T}}=-\frac{1}{U_{W}}-\frac{1}{H_{W}+H_{W G}}
\end{gathered}
$$

On the other hand, the radiative heat transfer coefficients $H_{G W}$ and $H_{W G}$ are related to one another as follows:

$$
H_{G W} \cdot A_{G}=H_{W G} \cdot A_{W}
$$

A convectional way of calculating the heating load by the use of $U$ value is

$$
Q=\left(U_{G} \cdot A_{G}+U_{W} \cdot A_{W}\right) \cdot\left(T_{A}-T_{0}\right)-I \cdot A_{G} \cdot \tau
$$

An exact way of calculating the heating load is to say that the heating load is the heat lost by the room air to the surrounding surfaces, or

$$
Q^{\prime}=H_{W} \cdot A_{W} \cdot\left(T_{A}-T_{S W}\right)+H_{G} \cdot A_{G} \cdot\left(T_{A}-T_{S G}\right) .
$$

In order to use the latter equation the values of $T_{S W}$ and $T_{S G}$ must be determined by solving eqs (A-1) and (A-2) simultaneously. Several sample calculations are performed as follows:

It is assumed that:

$$
\begin{aligned}
A_{G} & =10,32, \text { and } 100 \mathrm{ft}^{2} \\
A_{W} & =900 \mathrm{ft}^{2} \\
T_{A} & =70^{\circ} \mathrm{F} \\
T_{0} & =0^{\circ} \mathrm{F} \text { and } 40^{\circ} \mathrm{F} \\
U_{W} & =0.01,0.05,0.10 \text { and } 0.50 \mathrm{Btu} / \mathrm{h} \mathrm{ft}^{2}{ }^{\circ} \mathrm{F} \\
I & =0,100 \text { and } 200 \mathrm{Btu} / \mathrm{ft}^{2} \mathrm{~h} \\
H_{R G} & =0.918 \mathrm{Btu} / \mathrm{h} \mathrm{ft}^{2}{ }^{\circ} \mathrm{F} \\
H_{G} & =H_{W}=0.542 \mathrm{Btu} / \mathrm{h} \mathrm{ft}^{2}{ }^{\circ} \mathrm{F}
\end{aligned}
$$

Figure A-2 depicts the value of $R=Q^{\prime} / Q$ as affected by the value of $U_{W}$ for the case of $I=0$. On the other hand,

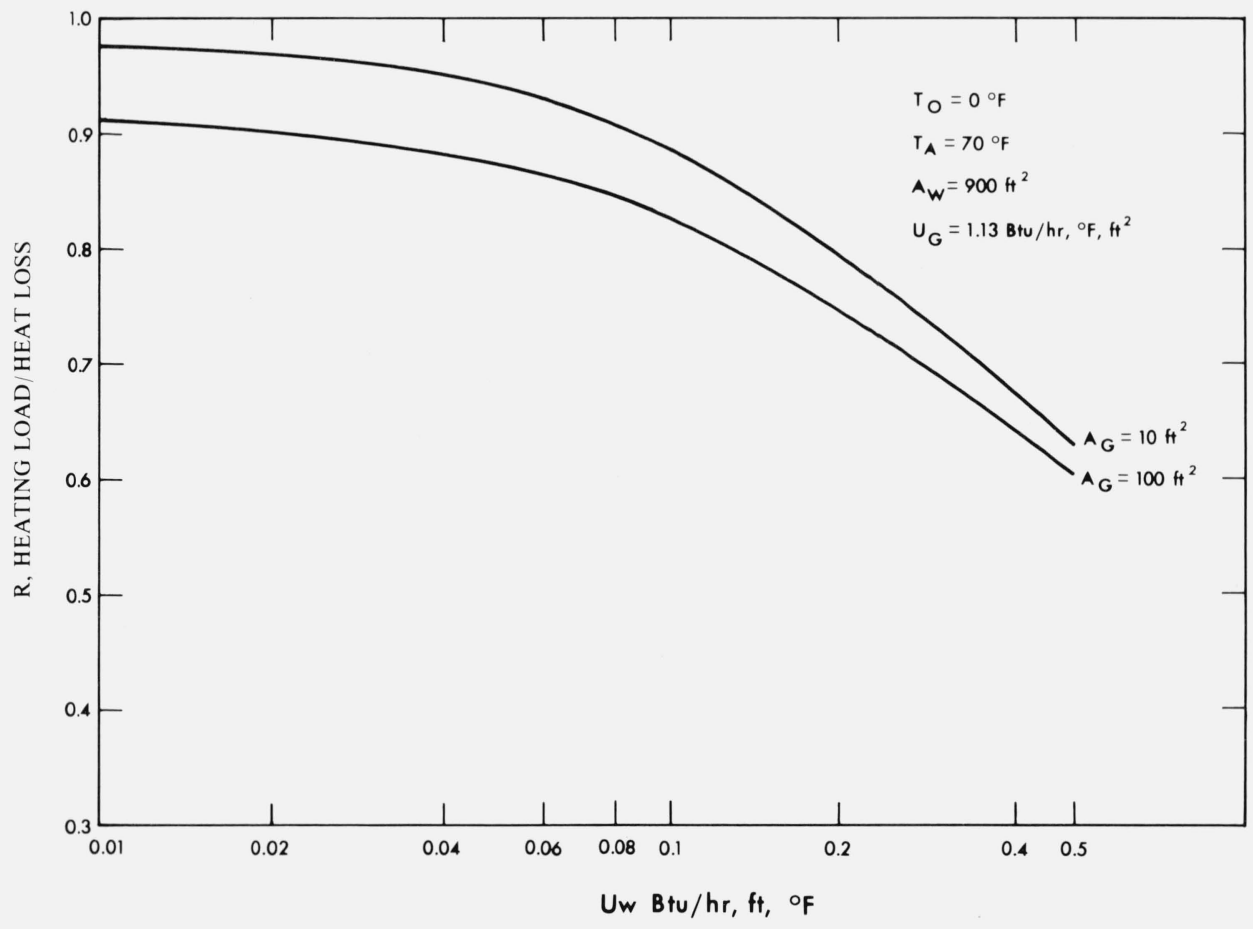

FIGURE A-2. Relationship between the heating load $\mathrm{Q}^{\prime}$ and heat loss $\mathrm{Q}$. 
TABLE A-1

\begin{tabular}{|c|c|c|c|c|c|c|c|c|}
\hline \multicolumn{4}{|c|}{$A_{W}=900 \mathrm{ft}^{2}$} & \multicolumn{2}{|c|}{$T_{A}=70^{\circ} \mathrm{F}$} & \multicolumn{3}{|c|}{$U_{W}=0$} \\
\hline$I$ & $U_{G} / \tau$ & $T_{0}$ & $A_{G}$ & $T_{S G}$ & $T_{S W}$ & $Q$ & $Q^{\prime}$ & $R$ \\
\hline 100 & $0.56 / 0.78$ & 0 & $\begin{array}{r}10 \\
32 \\
100\end{array}$ & $\begin{array}{l}43.7 \\
44.7 \\
47.8\end{array}$ & $\begin{array}{l}71.3 \\
74.1 \\
82.0\end{array}$ & $\begin{array}{lr}- & 502 \\
- & 1613 \\
- & 5074\end{array}$ & $\begin{array}{lr}- & 500 \\
- & 1573 \\
- & 4650\end{array}$ & $\begin{array}{r}1.00 \\
0.98 \\
.92\end{array}$ \\
\hline & & 40 & $\begin{array}{r}10 \\
32 \\
100\end{array}$ & $\begin{array}{l}59.1 \\
60.4 \\
64.1\end{array}$ & $\begin{array}{l}71.6 \\
75.0 \\
84.6\end{array}$ & $\begin{array}{l}-\quad 728 \\
-\quad 2340 \\
-\quad 9317\end{array}$ & $\begin{array}{lr}- & 723 \\
- & 2283 \\
- & 6802\end{array}$ & $\begin{array}{l}.99 \\
.98 \\
.93\end{array}$ \\
\hline & $1.13 / 0.87$ & 0 & $\begin{array}{r}10 \\
32 \\
100\end{array}$ & $\begin{array}{l}16.0 \\
16.3 \\
17.1\end{array}$ & $\begin{array}{l}71.0 \\
73.1 \\
78.9\end{array}$ & $\begin{array}{lr}- & 203 \\
- & 663 \\
- & 2084\end{array}$ & $\begin{array}{lr}- & 195 \\
- & 591 \\
- & 1453\end{array}$ & $\begin{array}{l}.96 \\
.89 \\
.70\end{array}$ \\
\hline & & 40 & $\begin{array}{r}10 \\
32 \\
100\end{array}$ & $\begin{array}{l}47.0 \\
47.5 \\
48.8\end{array}$ & $\begin{array}{l}71.6 \\
74.9 \\
83.9\end{array}$ & $\begin{array}{lr}- & 658 \\
- & 2112 \\
- & 6607\end{array}$ & $\begin{array}{lr}-\quad 647 \\
-\quad 2001 \\
-\quad 5620\end{array}$ & $\begin{array}{l}.98 \\
.95 \\
.85\end{array}$ \\
\hline 200 & $0.56 / 0.78$ & 0 & $\begin{array}{r}10 \\
32 \\
100\end{array}$ & $\begin{array}{l}44.4 \\
47.0 \\
54.2\end{array}$ & $\begin{array}{l}73.1 \\
80.0 \\
98.5\end{array}$ & $\begin{array}{l}-1402 \\
-4493 \\
-14074\end{array}$ & $\begin{array}{l}-\quad 1390 \\
-\quad 4388 \\
-13066\end{array}$ & $\begin{array}{l}.99 \\
.98 \\
.93\end{array}$ \\
\hline & & 40 & $\begin{array}{r}10 \\
32 \\
100\end{array}$ & $\begin{array}{l}60.0 \\
62.6 \\
70.6\end{array}$ & $\begin{array}{r}73.4 \\
80.7 \\
101.1\end{array}$ & $\begin{array}{l}-1630 \\
-5220 \\
-16317\end{array}$ & $\begin{array}{l}-1617 \\
-5098 \\
-15218\end{array}$ & $\begin{array}{l}.99 \\
.98 \\
.93\end{array}$ \\
\hline & $1.13 / 0.87$ & 0 & $\begin{array}{r}10 \\
32 \\
100\end{array}$ & $\begin{array}{l}16.2 \\
17.1 \\
19.6\end{array}$ & $\begin{array}{l}73.0 \\
79.4 \\
96.5\end{array}$ & $\begin{array}{l}-1203 \\
-3862 \\
-12084\end{array}$ & $\begin{array}{l}-1181 \\
-\quad 3649 \\
-10198\end{array}$ & $\begin{array}{l}.98 \\
.95 \\
.84\end{array}$ \\
\hline & & 40 & $\begin{array}{r}10 \\
32 \\
100\end{array}$ & $\begin{array}{l}47.3 \\
48.3 \\
51.3\end{array}$ & $\begin{array}{r}73.6 \\
81.1 \\
101.5\end{array}$ & $\begin{array}{l}-1658 \\
-5312 \\
-16607\end{array}$ & $\begin{array}{l}-\quad 1632 \\
-5058 \\
-14264\end{array}$ & $\begin{array}{l}.98 \\
.95 \\
.86\end{array}$ \\
\hline
\end{tabular}

table A-1 shows the case of solar heat gains $I=100$ and 200 being included for the calculations.

These results show that the error due to the assumption of the same air and exterior surface temperatures is rather small as long as the heat loss through the wall portion is small and the window area is less than $10 \%$ of the total room surface area. The conclusion is valid even in the case where the solar heat gain is included. 